NASA Technical Memorandum 105309

$1 N=20$

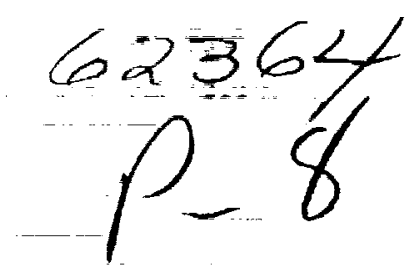

\title{
Nuclear Electric Propulsion: An Integral Part of NASA's Nuclear Propulsion Project
}

(NASA-TM-105309) NUCLEAR ELECTRIC PROPULSIUN: AN INTEGNAL PART OF NASA'S

낼
N92-16019

Unclas CSCL $21 \mathrm{H}$

\section{$63 / 20 \quad 0062364$}

James R. Stone

Lewis Research Center.

Cleveland, Ohio

Prepared for the

Ninth Symposium on Space Nuclear Power Systems

sponsored by the University of New Mexico

Albuquerque, New Mexico, January 12-16, 1992

\section{N/Sก}




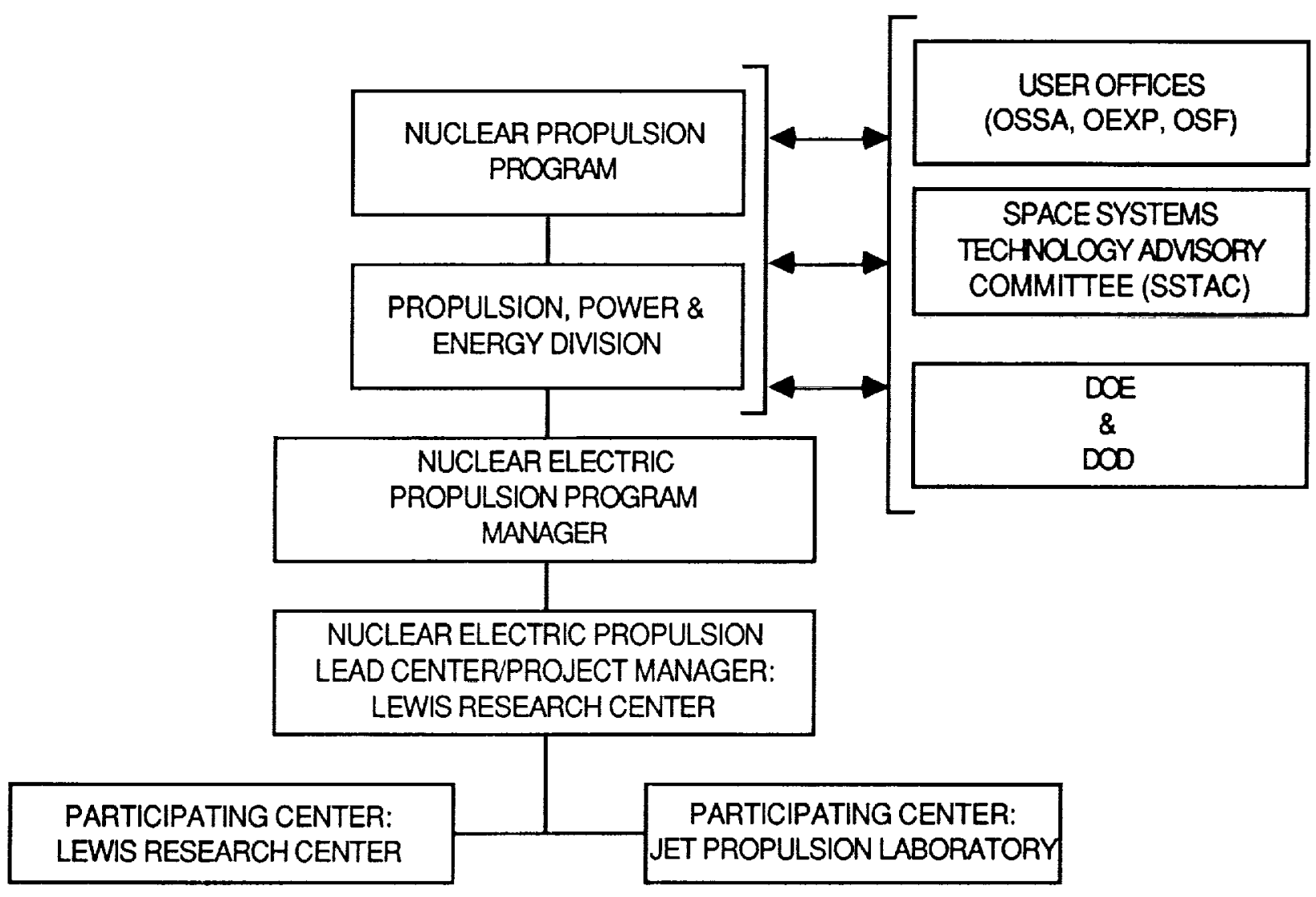

FIGURE 1. Nuclear Electric Propulsion Program Management Structure.

Interest in high power electric propulsion has been building for several years. The National Commission on Space (1986) advocated a number of challenging missions, such as a return to the Moon, unmanned and manned exploration of Mars and its moons, and unmanned scientific exploration of the rest of the solar system. Many of these missions would be enhanced, and some would be enabled by high $\mathrm{I}_{\mathrm{sp}}$ electric propulsion. To perform the challenging future missions, high power and high $\mathrm{I}_{\mathrm{sp}}$ systems will be required. Candidate thrusters include electrostatic (ion) and magnetoplasmadynamic (MPD) engines, with electrodeless approaches representing a longer term possibility. Electric propulsion is also applicable to advanced robotic exploration missions, offering both decreased propellant mass (and/or increased payload) and reduced trip times for deep space missions. There are also many potential applications for high $\mathrm{I}_{\mathrm{sp}}$ electric propulsion at the tens of kilowatts available from large solar power systems. High $\mathrm{I}_{\text {sp }}$ clearly offers propellant mass savings, but in order to practically exploit that benefit for space missions, it is necessary for the overall vehicle to exhibit acceleration levels sufficient to meet mission time lines. This requirement necessitates low specific mass and high efficiency propulsion and power systems in order to keep power system mass low.

The planning of the NEP Program builds on the earlier Cargo Vehicle Propulsion Program Plan (Stone 1988) augmented substantially by by a series of panel activities in support of the overall Nuclear Propulsion Project. These recent activities were initiated by workshops on NTP (Clark 1991) and NEP (Barnett 1991). These panels worked various planning issues and were coordinated through combined meetings and panel chairmen's meetings and were led by a DOE/DoD/NASA interagency steering group. Reports are being prepared by these panels, which were as follows: 
- Nuclear Safety Policy Working Group,

- Mission Analysis Panel,

- NTP Technology Panel,

- NEP Technology Panel,

- Nuclear Fuels/Materials Panel, and

- Test Facilities Panel.

\section{CURRENT PROIECT PLAN}

The original Project Plan was prepared in Fiscal Year (FY) 1990 in parallel with Worshops on NEP and NTP (Barnett 1991 and Clark 1991, respectively) with the target of reaching Technology Readiness Level (TRL) of 6 (Table 1) for NTP and TRL-5 for NEP in 2006, in time to support the Space Exploration Initiative (SEI). The plan has been updated as a result of the panel activities described in the preceeding paragraph and a series of interagency and NASA intercenter meetings(Clark and Miller 1991 and Doherty 1991). Because of the slower than anticipated funding growth, the TRL targets for both NTP and NEP have been delayed to 2009.

TABLE 1. $\quad$ NASA Technology Maturation Milestones for Space Application.

Level Description

Technology Development

1. Basic Principles Observed and Reported.

2. Technology Concept/Application Formulated.

3. Analytical and Experimental Critical Function and/or Characteristic Proof-of-Concept.

4. Component and/or Breadboard Validation in Laboratory.

5. Component and/or Breadboard Demonstrated in Relevant Environment.

6. System Validation Model Demonstrated in Relevant/Simulated Environment.

7. System Validation Model Demonstrated in Actual Environment.

\section{Advanced Development}

8. Technology Applied to Construction of Component and/or Breadboard of Expected Flight Hardware Configuration.

9. Capability of Full Scale Subsystem Protoype Demonstrated in Ground Tests.

10. Capability of Full Scale Subsystem Prototype Demonstrated in Actual Use.

Elight Hardware Development

11. Full Scale System Prototype.

12. Capability Demonstrated in Flight Test of Flight Hardware.

13. Capability Demonstrated by Operational Flight Experience.

The top level work breakdown structure (WBS) for the project is give in Table 2, which also includes more detail where work will be conducted in FY 1992. The planned work is described in more detail in the following paragraphs. 


\section{Project Management}

The Nuclear Propulsion Project Office coordinates the activities in various LeRC technology organizations, at the Marshall Space Flight Center (MSFC) (NTP) and at JPL (NEP). Coordination and communication with DoD and DOE laboratories are also important in management, particulary with regard to the nuclear sub-systems tasks, which are performed by DOE. The Idaho Engineering Laboratiry (INEL) has the lead in reactor systems, while the Los Alamos National Laboratory (LANL) has the lead in fuels development. This task also includes the development and implementation of a plan for informing the public of the rationale for SEI and the important role that nuclear propulsion will play in space exploration.

TABLE 2. Nuclear Propulsion Project Work Breakdown Structure (Elements Planned for First-Ycar Activity).

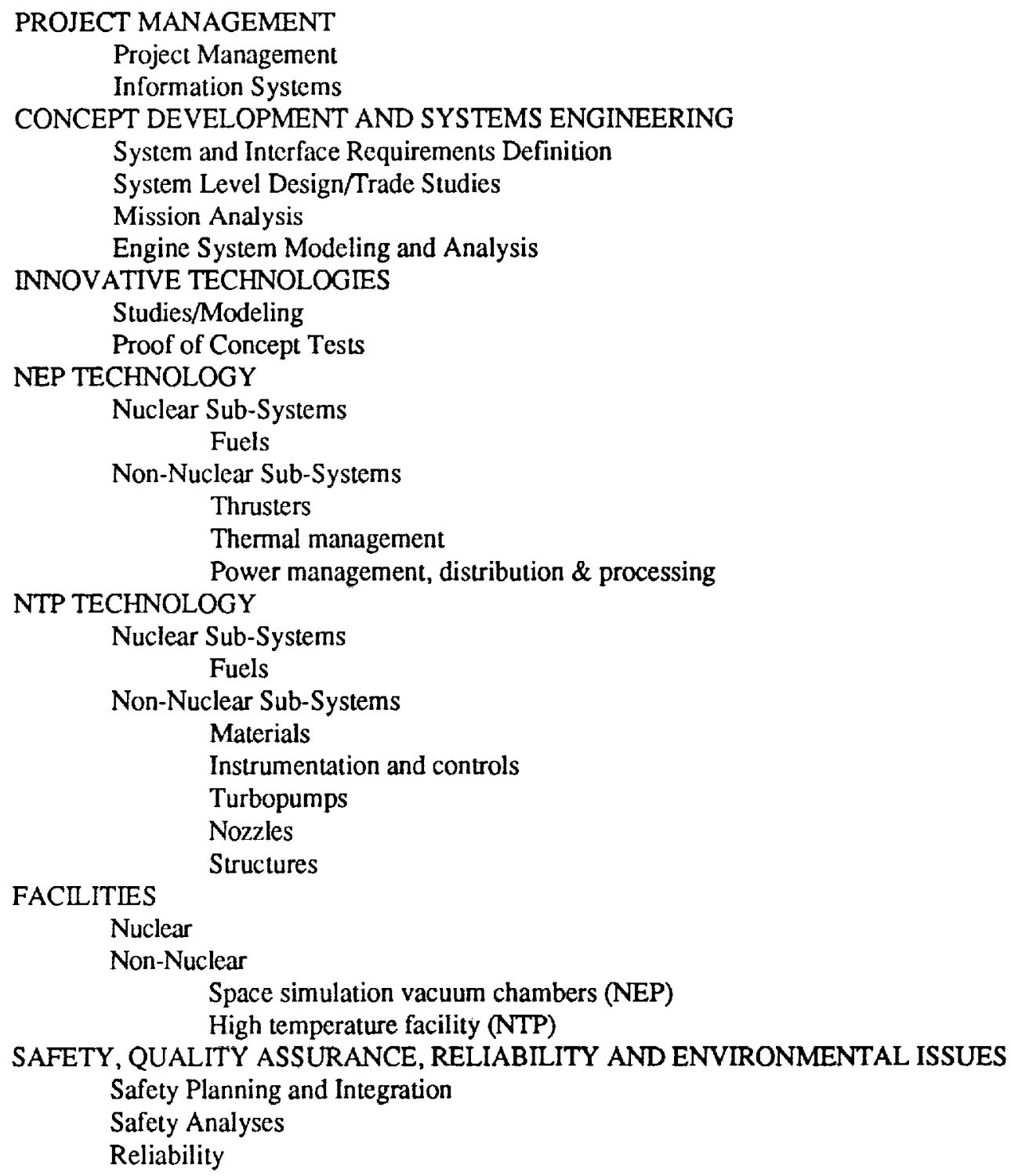




\section{Concept Development and Systes Engineering}

This effort was initiated in FY 1991 for NTP in the areas of requirements definition and engine system modeling and analysis. These activities will be accellerated in FY 1992, and further design work will be initiated with significant industry participation. For NEP the effort will focus on system level design/trade studies. These NEP studies will identify combinations of reactor, power conversion, heat rejection and thruster systems which show significant enough promise in one or more of the mission categories to warrant subsequent conceptual design studies.

\section{Innovative Technologies}

High-risk/high-payoff technologies for performance enhancements beyond the 2009 target levels will be pursued on a paced basis. Efforts will be initiated with studies and modeling leading to proof of concept tests. For those technologies achieving successfull proof of concept, concetual designs will be developed and critical components designed and tested.

\section{NEP Technology}

Most of the fuels activity in the early phase of this program will be on NTP since near-term NEP fuels will probably be derived from the SP-100 Program. The thruster technology will be focused primarily on MPD initially since ion propulsion is funded by the NASA Low Thrust Technology Program. The MPD effort at LeRC and JPL will concentrate on increasing power level and efficiency while also advancing the theoretical understanding of electrode phenomena. Advanced heat pipe technologies will be addressed in the Thermal Management area, while high temperature electronics will be the first activity under Power Management, Distribution and Processing.

\section{NTP Technology}

The NTP technology developments by LeRC, MSFC and DOE may also benefit the NEP Program. Potential areas of synergy include fuels (at a basic level), instrumentation and controls (radiation-tolerant, high temperature), and health monitoring.

\section{Eacilities}

Initial NTP facility activities will focus on high temperature hydrogen test capability. Early NEP facility activity will enhance existing capability of space simulation vacuum facilities by increasing the heat rejection and pumping capability resulting in increasing operating time at high power.

\section{Safety and Enyironmental Issues}

The initial activities in this area are largely common between NTP and NEP. Early activity will be primarily focused on planning and developing criteria appropriate for the ultimate piloted spacecraft application as well as ground testing issues. Preparation of Environmental Impact Statements will be initiated.

\section{CURRENT STATUS}

The NEP Program is underway at a significant pace, though not yet at a pace which assures our ability to meet the more aggressive proposed SEI timelines. The NEP effort is very much related to the ongoing SP-100 Program, but SP-100 currently addresses very general requirements, not specifically those of NEP. The status of advocacy for NEP is greatly improved over the recent past. NEP has often been proposed as enabling to many outer planetary missions, but received little serious attention or support from the space science community. Studies conducted in 1991 by JPL have done much to improve this situation and have aroused serious interest in the space science community (Yen 1991). Although Synthesis Group On America's Space Exploration Initiative (1991) selected NTP for piloted Mars missions, NEP was recommended for cargo applications. Recent LeRC studies (George, Hack and Dudzinski 1991) have shown that NEP may be quite competitive with NTP even for fast piloted missions to Mars. 


\section{CONCLUDING REMARKS}

The Nuclear Electric Propulsion Program (NEP) is accelerating toward the capability to support robotic and human exploration of the solar system. Interagency and intercenter cooperation is enabling significant progress in spite of the fragmented funding for this program - from the CSTI High Capacity Power Program, SP-100, and NASA's Base Research and Technology Program. Potential users of this technology, in both the space science and human exploration communities are becoming incresingly aware of the enhancing and enabling capabilities of NEP.

\section{Acknowledaments}

I would like to acknowledge the considerable efforts of other members of the LeRC Nuclear Propulsion Office, LeRC technologists, and all those who participated in the intercenter/interagency planning and panel activities.

\section{Beferences}

Advisory Committee on the Future of the U.S. Space Program (1990) Report of the Advisory Committee on the Future of the U.S. Space Program, U.S. Government Printing Office, Washington, DC.

Barnett, J.W. (1991) Proceedings of the NASAIDOE/DOD Nuclear Electric Propulsion Workshop, (JPL CPPasadena, CA, 19-22 June 1990.

Byers, D.C. and R.A. Wasel (1987) "The NASA Electric Propulsion Program," AIAA Paper 87-1098, May 1987.

Clark, J.S. (1991) Proceedings of the NASA/DOE/DoD Nuclear Thermal Propulsion Workshop. (NASA CPCleveland, $\mathrm{OH}, 10-12$ June 1990.

Clark, J.S. and T.J. Miller (1991) "The NASA/DOE/DoD Nuclear Rocket Propulsion Project," (AIAA Paper 91-3413), AIAA/NASA/OAI Advanced Technologies Conference, Cleveland, OH, 4-6 September 1991.

Doherty, M.P. (1991) "Blazing the Trailway: NEP and Its Technology Program Plans," (AIAA Paper 91-3441), AIAAINASAIOAI Advanced Technologies Conference, Cleveland, OH, 4-6 September 1991.

Hack, K.J., George, J.A. and L.A. Dudzinski (1991) "Nuclear Electric Propulsion Mission Performance for Fast Piloted Mars Missions," (AIAA Paper 91-3488), AIAA/NASA/OAI Advanced Technologies Conference, Cleveland, OH, 4-6 September 1991.

NASA (1988) Technology for Future NASA Missions: Civil Space Technology Initiative (CSTI) and Pathfinder, NASA CP-3016, Washington, DC, 12-13 September 1988.

NASA (1989) Project Pathfinder -- Program Plan -- Fall 1988, NASA Office of Aeronautics and Space Technology, Washington, DC, 27 January 1989.

National Commission on Space (1986) Pioneering the Space Frontier, Bantam Books, NY, June 1986.

Stone, J.R. (1988) Pathfinder Cargo Vehicle Propulsion Program Plan. NASA Office of Aeronautics and Space Technology, Washington, DC, November 1988.

Stone, J.R. and G.L. Bennett (1989) "The NASA Low Thrust Propulsion Program," AlAA Paper 89-2492, AIAA/ASME/SAE/ASEE 25th Joint Propulsion Conference, Monterey, CA, 10-14 July 1989.

Synthesis Group On America's Space Exploration Initiative (1991) America at the Threshold. Report of the Synthesis Group On America's Space Exploration Initiative, U.S. Government Printing Office, Washington, DC.

Yen, C.-W. (1991) "NEP Mission Study - Interim Report," Presented at NEP Technology Panel Meeting, NASA Lewis Research Center, Cleveland, OH, 18 July 1991. 
Public reporting burden for this collection of information is estimated to average 1 hour per response, including the time for reviewing instructions, searching existing data sources, gathering and maintaining the data needed, and completing and reviewing the collection of information. Send comments regarding this burden estimate or any other aspect of this Davis Highway, Suite 1204, Artington, VA 22202-4302, and to the Office of Management and Budget, Paperwork Reduction Project (0704-0188), Washington, DC 20503.

\begin{tabular}{|l|c|c|}
\hline 1. AGENCY USE ONLY (Leave blank) & $\begin{array}{r}\text { 2. REPORT DATE } \\
1991\end{array}$ & $\begin{array}{r}\text { 3. REPORT TYPE AND DATES COVERED } \\
\text { Technical Memorandum }\end{array}$ \\
\hline
\end{tabular}

4. TITLE AND SUBTITLE

Nuclear Electric Propulsion: An Integral Part of NASA's

Nuclear Propulsion Project

6. AUTHOR(S)

James R. Stone

\section{PERFORMING ORGANIZATION NAME(S) AND ADDRESS(ES)}

National Aeronautics and Space Administration

Lewis Research Center

Cleveland, Ohio $44135-3191$

9. SPONSORING/MONITORING AGENCY NAMES(S) AND ADDRESS(ES)

National Aeronautics and Space Administration

Washington, D.C. 20546-0001
5. FUNDING NUMBERS

WU-593-71-11

8. PERFORMING ORGANIZATION REPORT NUMBER

E- 6662

10. SPONSORING/MONITORING AGENCY REPORT NUMBER

NASA TM -105309

11. SUPPLEMENTARY NOTES

Prepared for the Ninth Symposium on Space Nuclear Power Systems sponsored by the University of New Mexico, Albuquerque, New Mexico, January 12-16, 1992. Responsible person, James R. Stone, (216) 977-7120.

12a. DISTRIBUTION/AVAILABILITY STATEMENT

12b. DISTRIBUTION CODE

Unclassified - Unlimited

Subject Category 20

13. ABSTRACT (Maximum 200 words)

The National Aeronautics and Space Administration (NASA) has initiated a technology program to establish the readiness of nuclear propulsion technology for the Space Exploration Initiative (SEI). This program was initiated in the past fiscal year with a very modest effort identified with nuclear thermal propulsion (NTP); however, nuclear electric propulsion (NEP) is also an integral part of this program and builds upon NASA's Base Research and Technology Program in power and electric propulsion as well as the SP-100 space nuclear power program. Although the Synthesis Group On America's Space Exploration Initiative has identified NEP only as an option for cargo missions, recent studies conducted by NASA Lewis show that NEP offers the potential for the early manned Mars missions as well. Lower power NEP is also of current interest for outer planetary robotic missions. This paper reviews current plans for the overall nuclear propulsion project, with emphasis on NEP and those elements of NTP program which have synergism with NEP.

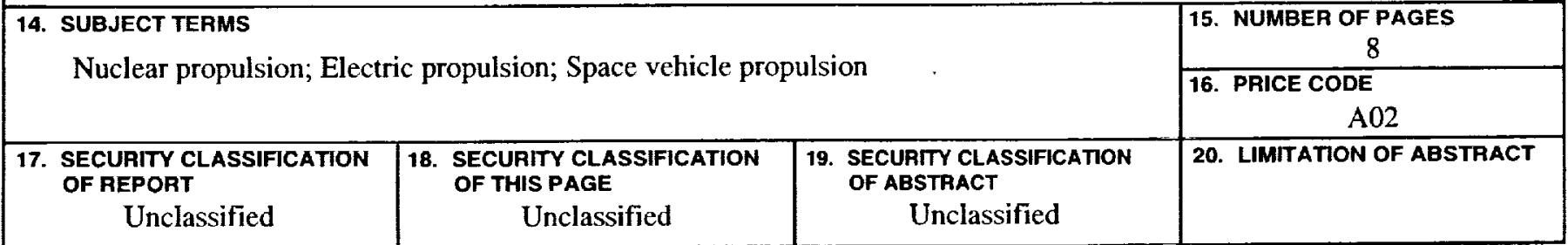

